\title{
A ORGANIZAÇÃO CURRICULAR E A AVALIAÇÃO DA APRENDIZAGEM COMO DISPOSITIVOS PEDAGÓGICOS: UMA EXPERIÊNCIA EM EJA
}

THE CURRICULUM ORGANIZATION AND ASSESSMENT AS PEDAGOGICAL DEVICES: AN EXPERIENCE WITH ADULT EDUCATION

ORGANIZACIÓN DEL CURRÍCULO Y EVALUACIÓN DEL APRENDIZAJE COMO DISPOSITIVOS PEDAGÓGICOS: UNA EXPERIENCIA EN LA EDUCACIÓN DE JÓVENES Y ADULTOS

\section{Luiz Antonio Saléh Amado*}

\begin{abstract}
RESUMO
Este artigo problematiza os efeitos provocados pela integração curricular e pela alteração das formas de avaliar a aprendizagem nas práticas pedagógicas cotidianas e no modo de subjetivação de professores da educação de jovens e adultos (EJA) de uma escola pública federal. Com base na revisão da literatura sobre o tema, na participação efetiva nos espaços coletivos de discussão e no relato da experiência dos educadores, descreve as dificuldades e as resistências surgidas durante tal processo. Destaca o papel do currículo integrado e da avaliação da aprendizagem como dispositivos pedagógicos, permitindo colocar em discussão as relações e as práticas instituídas. Conclui apontando a importância de se criarem condições de possibilidade para que tanto professores quanto alunos discutam as relações e as práticas assumidas como naturais à educação, com vistas a instaurar fazeres pedagógicos instituintes e que potencializem as discussões, favorecendo o surgimento de estratégias educacionais implicadas com a transformação social.
\end{abstract}

Palavras-chave: Currículo integrado. Avaliação da aprendizagem. Educação de jovens e adultos.

\section{ABSTRACT}

This article discusses the effects caused on everyday teaching practices and on the subjectification of teachers of adult and young learners education in a federal public school with integrated curriculum and changes on the assessment process. Based on literature reviewed, effective participation in collective spaces for discussion and reporting of educators experience, describes the difficulties and resistances that arise during this process. It also

\footnotetext{
Texto recebido em 2 de agosto de 2013 e aprovado para publicação em 30 de junho de 2015.

Doutor em Psicologia Social pela Universidade do Estado do Rio de Janeiro (UERJ), professor permanente do Programa de Pós-Graduação em Políticas Públicas e Formação Humana (PPFH-UERJ), professor adjunto do Departamento de Ciências e Fundamentos da Educação da Faculdade de Educação da Baixada Fluminense (DCFE/FEBF/UERJ). E-mail: saleh.amado@ gmail.com.
} 
highlights the role of the integrated curriculum and learning assessment as pedagogical devices. It emphasizes the importance of creating conditions of possibility for both teachers and students to discuss the relationships and practices assumed as natural to education, it enhances the discussions, by favoring the emergence of educational strategies involved with social transformation.

Keywords: Curricular integration. Learning assessment. Adult education.

\section{RESUMEN}

Este artículo aborda los efectos causados por la integración curricular y por la alteración de las formas de evaluar el aprendizaje en las prácticas pedagógicas cotidianas y en el modo de subjetivación de profesores de EJA (educación de jóvenes y adultos) de una escuela pública federal. Con base en la revisión de la literatura sobre el tema, en la participación efectiva en los espacios colectivos de discusión y en el relato de la experiencia de los educadores, describe las dificultades y resistencias que surgen durante este proceso. Pone de relieve el papel del currículo integrado y evaluación del aprendizaje como dispositivos pedagógicos que permiten analizar las relaciones y prácticas instituidas. Concluye destacando la importancia de crear condiciones de posibilidad para que los profesores y los alumnos discutan las relaciones y las prácticas asumidas como naturales de la educación, con el fin de ampliar las discusiones, favoreciendo la aparición de estrategias educativas implicadas con la transformación social.

Palabras clave: Integración curricular. Evaluación del aprendizaje. Educación de jóvenes y adultos.

\section{INTRODUÇÃO}

perspectiva da educação baseada no currículo integradovem se materializando
nos últimos anos por meio de inúmeras ações e programas nos diferentes
níveis e modalidades de ensino. Os documentos que orientam a educação de maneira geral, como é o caso da Lei de Diretrizes e Bases da Educação Nacional (LDB 9.394/1996), criticam a fragmentação e a compartimentalização dos saberes em disciplinas, reforçando o discurso em favor da organização curricular integrada, e, ao mesmo tempo, preconizam a interdisciplinaridade e a contextualização como estratégias para articular e integrar conhecimentos.

No caso da educação de jovens e adultos (EJA), temos o exemplo do Programa de Integração da Educação Profissional ao Ensino Médio na Modalidade de Educação de Jovens e Adultos (Proeja). Como a própria denominação do programa demonstra, há o interesse explícito em vincular a educação profissional 
à educação básica, tendo como princípio a integração. O Documento-Base do Proeja (Brasil, 2006) anuncia a intenção de superar a dualidade histórica entre cultura geral e cultura técnica, presente na educação brasileira.

Entretanto o rompimento com a lógica que distingue a formação humana de maneira ampla da educação para o trabalho é apenas um dos efeitos esperados ao se adotar a integração curricular como referência do fazer pedagógico. Como pode ser visto nos documentos da educação básica, os quais orientam as discussões das diversas áreas de conhecimento para a construção de seus respectivos currículos, a proposta de organização curricular integrada também busca reunir aquilo que as disciplinas separaram ao longo de vários anos, obedecendo à lógica fragmentar, própria da racionalidade produzida na Modernidade. Para alcançar esse objetivo, todavia, é necessário colocar em discussão os fazeres e as relações pedagógicas, resultando na efetiva análise das práticas profissionais dos professores.

Este artigo tem por objetivo problematizar os efeitos provocados nas práticas pedagógicas cotidianas e no modo de subjetivação de um grupo de professores da EJA/Proeja de uma escola da rede pública federal, com base na organização do fazer pedagógico com base na integração curricular. A experiência relatada ganha consistência quando os docentes da EJA dessa escola (incluindo-se aqui a coordenação) ${ }^{1}$ optam por alterar a maneira como desenvolvem a avaliação da aprendizagem dos alunos, criando condições para que tanto professores quanto alunos discutam as relações e as práticas assumidas como naturais à educação, com vistas a instaurar fazeres pedagógicos distintos dos instituídos.

É evidente que a EJA (seu público, suas especificidades, etc.) provoca a educação a sair do lugar instituído no qual tem se mantido há tanto tempo. Todavia, no âmbito das experiências oficiais de educação de adultos, até hoje não havia surgido alguma proposta que fosse capaz de desafiar a educação a pensar mais intensamente seus processos, desestabilizando práticas e relações cristalizadas ao longo dos anos. Durante muito tempo, a educação de adultos no Brasil foi tratada como uma modalidade de ensino cuja função era, predominantemente, alfabetizar. Destinada a um público do qual pouco se esperava e, ao mesmo tempo, no qual pouco se investia, diferentes governos se sucederam, mas as ações voltadas para essa parcela da população se restringiam a compensar a reconhecida falta de oportunidades de acesso ao ensino regular.

Ao orientar a organização do fazer pedagógico dos cursos destinados aos adultos sob as bases do currículo integrado, o Proeja consegue, inclusive, reverberar em outras direções, lançando o debate para além da fronteira da educação de

\footnotetext{
O lugar do qual falo é o de um dos componentes da coordenação da EJA da referida escola. O grupo de coordenadores, formado então por uma pedagoga, uma professora de Língua Portuguesa e um psicólogo, assumiu a tarefa de reorganizar a educação de jovens e adultos a partir do pedido da direção, em 2010. Desde o princípio, a coordenação optou pelo trabalho em parceria com o grupo de professores, a fim de estabelecerem estratégias de atuação conjuntas.
} 
jovens e adultos. Quando o programa deflagra discussões acerca da organização curricular, é toda a educação que é questionada (as formas de organização das relações, das práticas, dos tempos e dos espaços) e não apenas uma de suas modalidades. Assim fazendo, os professores são desafiados a problematizar as práticas pedagógicas naturalizadas e, portanto, supostamente imunes às críticas e aos questionamentos.

Tanto o currículo integrado quanto a avaliação da aprendizagem são encarados neste artigo como dispositivos pedagógicos, considerando-se o conceito cunhado por Larrosa (1994), com base no pensamento foucaultiano. De acordo com o autor, os dispositivos pedagógicos (por exemplo, qualquer prática pedagógica com certas regras e certas formas de realização) devem ter sua contingência e historicidade reconhecidas e, como deflagradores da experiência de si, são tomados como constitutivos da subjetividade (Larrosa, 1994).

$\mathrm{Na}$ experiência aqui relatada, além dos efeitos que a discussão sobre a organização curricular pode provocar, as mudanças do processo de avaliação da aprendizagem empreendidas pelo grupo de professores permitem afirmar que, se para alguns, a EJA é considerada um apêndice da Educação, sendo desenvolvida segundo práticas e discursos pedagógicos próprios de outras modalidades que a estranham, para nós, é possível encará-la como um analisador, ${ }^{2}$ posto que evidenciam o modo como a Educação e as práticas docentes se constituem, tornando possível o surgimento de outras formas de organização do fazer pedagógico.

Nesse sentido, para dar sequência a este artigo, os dispositivos pedagógicos currículo integradoe avaliação de aprendizagem são apresentados, respectivamente, nos dois tópicos seguintes, buscando-se problematizar o potencial transformador das práticas pedagógicas. A estratégia metodológica usada para a apresentação da experiência descrita neste artigo se fundamenta na revisão da literatura sobre os dois dispositivos citados e no material colhido a partir da participação efetiva nos espaços coletivos de discussão.

\section{O DISPOSITIVO PEDAGÓGICO CURRÍCULO INTEGRADO}

Por ser um programa que objetiva a integração da educação básica com a educação profissional, o Proeja desafia os educadores a trabalharem na perspectiva do currículo integrado. Este tem sido, sem dúvida, um dos maiores obstáculos para a construção dos cursos. Não existe uma fórmula ou modelo para se colocar em movimento a organização curricular nesses termos, o que obriga os

\footnotetext{
No sentido que lhes dá a análise institucional, os analisadores são todos aqueles dispositivos ou acontecimentos que permitem o aparecimento de movimentos diferentes dos que funcionam "naturalmente", pela possibilidade de colocar em discussão a maneira como as relações e as práticas institucionais se organizam numa dada situação.
} 
educadores envolvidos a se mobilizarem para pensar estratégias, propor arranjos, em suma, definir coletivamente como se efetivará a integração do currículo no âmbito de seus cursos. De acordo com Machado (2005), por exemplo, há diversas abordagens metodológicas de integração dos currículos, entre as quais é possível citar a abordagem por área de conhecimentos, a mediada por dilemas reais vividos pela sociedade, a centrada na resolução de problemas, a abordagem por meio de esquemas conceituais e embasada na perspectiva de complexos temáticos.

Embora já exista a oferta de ensino médio integrado para adolescentes (educação "regular"), essa integração pode se referir apenas ao modo diferenciado das formas subsequente e concomitante, ou seja, o modo integrado pode indicar, simplesmente, que as disciplinas que compõem a formação (ensino técnico e ensino médio) são cursadas ao mesmo tempo e, obrigatoriamente, no mesmo estabelecimento de ensino.

De todo modo, algumas tentativas vêm sendo feitas por educadores preocupados e, sobretudo, interessados em oferecer alternativas às práticas pedagógicas tradicionais, entre outras razões, por perceberem as insuficiências dessas práticas. Por isso mesmo, algumas estratégias descritas nos trabalhos relacionados ao Proeja estão baseadas em experiências que vêm sendo empreendidas por docentes envolvidos não necessariamente ou, pelo menos, não exclusivamente com a educação de jovens e adultos. Entre tais estratégias, podemos citar a metodologia de projetos, o trabalho com eixos integradores, a prática por intermédio de atividades integradoras, entre outras.

Pode-se questionar, contudo, como sugere Silva (2010a), se a Rede Federal tem conseguido praticar a integração para esses cursos. Para a efetivação da integração curricular, são necessárias condições que nem sempre estão presentes no cotidiano de trabalho educacional. Sem a discussão coletiva, sem o mínimo de tempo e espaço para que os profissionais envolvidos se encontrem, não há condições para a construção de outras práticas. Nas palavras da autora, "não há como repensar a organização curricular sem repensar a organização de pessoal, de infraestrutura, materiais e pedagógicas, das condições de trabalho dos profissionais" (Silva, 2010a, p. 137).

Para além das dificuldades causadas pela falta de condições materiais e estruturais, a integração curricular esbarra ainda nas resistências de professores que, marcados pela formação recebida e, em muitos casos, presos às práticas que vêm instrumentalizando desde então, não conseguem problematizá-las nem repensar outras possibilidades de atuação. 
Essa situação se apresenta no relato de inúmeras experiências do Proeja. $\mathrm{Na}$ pesquisa sobre a implementação do Proeja na Rede Federal, Silva (2010b) aponta que, mesmo quando se consegue instituir o espaço de reflexão na escola, é possível observar que as discussões não atingem igualmente os dois grupos de profissionais do Programa (professores da formação geral e do ensino técnico), deixando à mostra que a prática de dar aulas se torna mais importante do que o sentido que essas aulas devem ter.

O relatório final do Diálogos Proeja, ${ }^{3}$ realizado em março de 2009 pelo Instituto Farma de Governança Operacional (IFGO) (Adriano, Guimarães \& Oliveira, 2009), aponta que as reuniōes pedagógicas não devem privilegiar os aspectos administrativos, mas sim as reflexôes sobre a prática docente. Além disso, chama a atenção para que os professores estejam abertos ao diálogo com outros professores e que a instituição deve favorecer o encontro regular de todos os profissionais.

Em certos casos, no processo de discussão que precedeu (ou que acompanha) a implantação do Programa nas Escolas da Rede Federal, surgem situações de tensão, como a descrita por Moura et al. (2011) no grupo de educadores do Instituto Federal do Espírito Santo (IFES/ES). Essa tensão pode ter origem no confronto de ideias e de concepções distintas de educação, mas quase sempre dificultam o diálogo ou até inviabilizam a construção de alternativas:

De fato, essa tensão mostrou-se evidente nos debates dos grupos das comissōes quando da necessidade de reconhecer o Proeja como um curso diferenciado dos demais até então ofertado pelas coordenadorias. Foi preciso uma postura vigilante por parte de alguns dos membros das comissōes perante tentativas de equalizar as propostas em discussão a outras realidades educativas existentes na instituição e diferentes da modalidade EJA. A ideia subjacente a tais tentativas era de que os alunos seriam todos iguais, não sendo consideradas assim as especificidades dos sujeitos da EJA, desmerecendo a necessidade de um tratamento didático-pedagógico diferenciado (Moura et al., 2011, p. 8).

É importante afirmar a crítica necessária à tentativa de se aplainar as diferenças entre a EJA e as outras modalidades, com o objetivo de converter os discursos sobre o currículo integrado em algo assimilável pelos modelos conhecidos. A situação apresentada pelo educador do IFES/ES parece indicar a resistência diante de possíveis mudanças, principalmente se estas implicam a possibilidade de destinarem ao professor o trabalho com um público estigmatizado nos meios educacionais. Como exemplo, um desses estigmas é a crença de que as pessoas

O Diálogos Proeja faz parte de um conjunto de açōes desenvolvidas pelo Ministério da Educação (MEC)/Secretaria de Educação Profissional e Tecnológica (Setec) com vistas a incentivar a implementação dos cursos Proeja na Rede Federal de Ensino. No caso específico do Diálogos, entre os objetivos principais, podem-se citar o estímulo à troca de experiências, a discussão e o encaminhamento de propostas visando à superação dos desafios pedagógicos surgidos, e a integração das ações desenvolvidas. 
nessa condição (alunos da educação de jovens e adultos) são responsáveis pelo seu próprio insucesso escolar.

É preciso chamar a atenção para outro aspecto que emerge dos debates e análises oriundos da inserção da EJA no sistema de ensino de uma forma mais sistemática. Se as teorias do desenvolvimento pouco falam do adulto e se isso traz consequências para o trabalho pedagógico que é feito com ele, vale lembrar que a educação de jovens e adultos possibilita inúmeras oportunidades de olhar para as diferenças, mais do que para as regularidades ou permanências. Com isso, embora reafirme a necessidade do respeito às especificidades tanto de adultos quanto de crianças, considero urgente estender as críticas à educação proporcionadas pela construção da integração curricular (via Proeja) ou pela inserção atual da EJA em muitas escolas a todas as outras modalidades e não somente à educação de jovens e adultos. Em suma, se cada modalidade de ensino nos obriga a observar suas especificidades, as críticas que surgem a partir do trabalho na EJA devem ir além dos seus limites, permitindo que nosso olhar se volte para aspectos gerais do fazer pedagógico, os quais costumam ser vistos, porém não notados.

A concepção que orienta nossas discussões sobre integração curricular está assentada na ideia de que as formações curriculares produzidas pela pedagogia moderna resultam de um modo de pensar que distribui os saberes num suposto espaço epistemológico, funcionando, de acordo com Veiga-Neto (2002), como "condição de possibilidade para a fragmentação dos saberes modernos em disciplinas" (Veiga-Neto, 2002, p. 206).

Conforme apontam Lopes e Macedo (2011), na esteira do pensamento de Veiga-Neto, no lugar de fixar as críticas em torno de um único ponto (a disciplinarização dos saberes), mais produtivo seria entender as relações entre organização curricular e transformações espaçotemporais, uma vez que, ao longo do tempo, o currículo tanto foi produto quanto produziu modos de pensar. O currículo é considerado, então, um dispositivo que atua no processo de constituição dos sujeitos. Consequentemente, as práticas e as estratégias pedagógicas que são efetivadas com base nele incidem diretamente na produção de subjetividades.

Antes de finalizar estas observações sobre o currículo integrado, é necessário citar algumas pesquisas sobre o assunto. A primeira se refere à abordagem interdisciplinar. Menegotto, Ayub e Perozzo (2009) caminharam por esse tipo de abordagem e alegam que, diante da multiplicidade de interações e negações recíprocas, a relação entre as disciplinas tradicionais pode ir da simples comunicação de ideias até a integração mútua de conceitos (p. 69). Reconhecem, contudo, que, apesar dos esforços, pouco estão conseguindo fazer avançar nessa 
direção, pois é comum conservar a lógica de funcionamento fragmentado das disciplinas, segundo a qual os componentes curriculares permanecem isolados e compartimentados.

Em duas outras pesquisas, os autores fazem críticas fundamentais à forma como a integração curricular vem sendo efetivada em algumas experiências do Proeja. Na primeira delas, Colontonio (2010) destaca que o eixo trabalho, cultura, ciência e tecnologia, proposto para produzir a integração entre formação geral e profissional, pode estar atrelado a um imperativo social de racionalização instrumental do conhecimento. A autora defende a problematização desse eixo, baseando-se na hipótese de que os conceitos que o compõem foram enunciados pelas diretrizes do Programa de modo acrítico e a-histórico, limitando a formação integrada e integral dos indivíduos.

De modo bastante direto e contundente, a autora afirma que o texto legal não é suficiente para estabelecer determinadas práticas, mas pode redefinir, ou pelo menos desacomodar, práticas até então absolutas. Esse movimento ocorre em meio a mudanças e resistências. Porém desse duplo movimento pode emergir um novo produto, diferente do que fora prescrito. Conclui chamando a atenção para as ações efetivadas pelos agentes diretamente responsáveis pela instrumentalização da integração curricular e o que está prescrito nas diretrizes. Nas análises que empreende nos documentos e planos de curso do Proeja salienta

Que a concepção de integração a partir do eixo ciência, cultura, trabalho e tecnologia está muito mais próxima das açôes dos sujeitos - professores, alunos, gestores - do que da concepção de integração entre os conhecimentos. Nos planos de curso e em suas diretrizes não há manifestação de integração entre as disciplinas de forma a criar novos conhecimentos ou conhecimentos integrados que ultrapassem a divisão disciplinar e hierarquização dos conteúdos. $\mathrm{O}$ que encontramos nas prescriçóes curriculares são previsóes de que a integração ocorrerá a partir de um diálogo entre as disciplinas e pela troca de experiências metodológicas entre os professores. Revela-se, assim, a materialização do conceito de integração em ações individuais e em metodologias, muito distante da discussão necessária para a quebra das barreiras entre as diferentes áreas - e professores das diferentes disciplinas - de conhecimento e as possibilidades de integração entre os diferentes estatutos teóricos (Colontonio, 2010, p. 104).

$\mathrm{Na}$ outra pesquisa que merece destaque, Lopes (2009) analisa a implantação do Programa numa escola agrotécnica da Rede Federal, buscando verificar qual a relação entre a denominada integração expressa no discurso oficial, a proposta da escola e a prática educativa constituída na realidade da escola. De acordo com o autor, o currículo integrado, como conceito e proposta de trabalho, pode ser reduzido, na prática, a um simples slogan a serviço de interesses 
políticos. É preciso reconhecer a dicotomia entre o que é colocado no papel e o que efetivamente é realizado no cotidiano. Afirma ainda que a formação dos professores é pautada no modelo disciplinar, o que confere grande dificuldade para que possam reformular sua prática. Por fim, resume alguns aspectos que, na visão dos entrevistados, seriam responsáveis pela dificuldade do trabalho na perspectiva do currículo integrado:

Os dados da pesquisa sugerem que a falta de experiência dos professores/professoras em trabalhar com as especificidades da EJA é um fator que dificulta o trabalho docente no PROEJA. Ao lado disso, de acordo com os entrevistados, alguns fatores dificultam a integração entre a educação profissional e a educação básica na modalidade EJA, como, por exemplo: (a) não fazer a discussão sobre a integração; (b) dificuldade de se colocar em prática o planejamento; (c) falta de tempo dos professores para se encontrarem e conversarem entre si; (d) carga horária reduzida do PROEJA; (e) desconhecimento do que vem a ser currículo integrado e (f) disputa que se estabelece entre as disciplinas (hierarquização ou estratificação do conhecimento escolar) no campo do currículo (Lopes, 2009, p. 170).

Dos pontos levantados acima, depreende-se que é extremamente necessária outra organização do cotidiano de trabalho docente, evitando-se o distanciamento e o isolamento. Uma estratégia importante se refere à regularidade de reuniōes entre os professores. Estes encontros, todavia, precisam ser planejados de forma que não se transformem em reuniões burocráticas, onde se trate principalmente de assuntos administrativos. Outro problema que costuma ocorrer com esse tipo de reunião está relacionado ao número de participantes. Não se trata de especificar um número ideal, mas sim ficar atento para o fato de que o aumento do número de professores nas reuniões, além de tornar sua condução mais difícil em razão da dispersão, tende a dificultar o entrosamento e o desenvolvimento de atividades envolvendo todo o grupo, apontando, portanto, para a necessidade de se desenvolverem estratégias que garantam o funcionamento do grupo de forma ativa e participativa.

\section{O DISPOSITIVO PEDAGÓGICO AVALIAÇÃO DA APRENDIZAGEM}

A experiência a ser relatada diz respeito ao processo de formação docente entendido como algo que se estende pelo cotidiano da prática. Nesse sentido, a partir do estabelecimento da nova coordenação da EJA numa escola federal, responsável pela preparação das bases para uma turma do Proeja que seria implantada na escola, buscou-se desenvolver coletivamente com os professores a prática de construção da proposta pedagógica. 
Os primeiros encontros entre o grupo de professores e a coordenação destinavam-se a um processo de reconhecimento mútuo, além de permitir aos coordenadores conhecer a metodologia, os instrumentos, os recursos, os processos de avaliação, a coesão dos trabalhos realizados entre as disciplinas afins e entre todas as disciplinas, assim como a análise de cada professor em relação ao processo de ensino-aprendizagem ocorrido até então. Pouco a pouco, pela adoção de dispositivos coletivos de discussão (reuniōes semanais do grupo de educadores, planejamento conjunto das atividades, entre outros), foram sendo estabelecidas as bases necessárias à alteração de algumas práticas mais gerais, ao mesmo tempo em que se ampliava a capacidade de repensar e propor ações e estratégias educacionais que escapassem à repetição e proporcionassem possibilidades efetivas de mudança.

Uma das principais alterações promovidas incidiu sobre os processos de avaliação da aprendizagem. Motivados pela possibilidade de abandonar as tradicionais notas como determinantes da aprovação ou reprovação dos alunos, os professores optaram por utilizar outros modos de avaliação que dispensassem a quantificação da aprendizagem por meio de números ou mesmo conceitos.

A avaliação tem sido considerada o ponto culminante do processo de ensino e aprendizagem. E isso ocorre porque se distorce o sentido da formação, tratandose a avaliação como fim e não como meio. A necessidade de se repensarem os processos avaliativos se impõe em todas as modalidades de ensino, mas, no caso específico do aluno da EJA, reveste-se de significados um pouco diferentes, sobretudo quando consideramos as razóes que um dia levaram esses alunos a se afastarem da escola. Por estar-se diante de um sujeito cuja confiança na sua capacidade de ser bem-sucedido nas tarefas escolares pode ter sido abalada, será preciso não apenas repensar os objetivos da avaliação, como trabalhar junto aos alunos para que construam outro tipo de relação com esse instrumento pedagógico.

De acordo com a discussão empreendida no encontro Diálogos Proeja, realizada pelo IF de Goiás,

A avaliação não pode ser instrumento punitivo, que oferece ao aluno a sensação de impotência e de diminuição perante o outro. Deve ser integrada ao processo e, aqui, cabe ao professor conduzir suas aulas de maneira a desconstruir o paradigma da avaliação estática e familiarizar os seus discentes com a avaliação integradora, com capacidade de localizar onde devem melhorar, se esforçar mais e colaborar com o professor na busca de novas estratégias (Adriano et al., 2009, p. 121). 
Retornando à experiência objeto deste relato, é interessante observar os efeitos analíticos da supressão da nota sobre a prática pedagógica e, principalmente, sobre a prática avaliativa dos professores. Ao proporem outras formas de avaliação e, mais precisamente, índices diferentes das notas e hierarquizaçôes para definir a aprovação ou reprovação do aluno, os professores sentem a necessidade de adotar algum referencial que permita informá-los acerca do desempenho dos estudantes. Com base nas discussões empreendidas, percebe-se a reconstrução do raciocínio que leva à conclusão de que as notas cumpririam essa função. Entretanto os professores percebem rapidamente o equívoco embutido nesse raciocínio. A suposta capacidade de informar como os alunos se conduziram durante determinado período não é senão uma frágil construção que é abalada ao menor questionamento acerca das condiçôes sob as quais aquelas notas foram obtidas. Os professores são levados, assim, a pensar mais detidamente sobre os objetivos da avaliação. Decide-se manter a avaliação apartada das notas e investir em formas processuais de avaliar, ${ }^{4}$ propondo-se, então, a ficha de acompanhamento dos alunos, cuja função é registrar seus movimentos e transformações ao longo do semestre. A construção das fichas obedeceu a alguns princípios básicos: a proposta pedagógica da EJA, as especificidades de cada área de conhecimento e o reconhecimento da importância da participação dos próprios sujeitos no processo avaliativo. Após alguns encontros que tiveram como objetivo ajustar certos parâmetros comuns à proposta pedagógica, cada professor desenvolveu o seu modelo de ficha de acompanhamento, variando num ou noutro aspecto, mas buscando preservar o interesse comum de incluir os alunos na ação de avaliar. Nesse processo, é possível o uso de quaisquer instrumentos de avaliação (tradicionais, como provas, ou não), desde que o objetivo continue sendo o envolvimento dos alunos no processo de ensino/aprendizagem e não a reprodução da lógica instrumental que desvia as atenções da construção de conhecimentos para a obtenção de graus ou conceitos.

Entre os parâmetros que podem ser usados para verificar a validade dessa iniciativa, é possível citar a redução no índice de evasão dos alunos, se comparados aos de semestres anteriores, quando se utilizavam métodos tradicionais de avaliação da aprendizagem. Outro ponto que merece destaque, e que mantém estreita relação com o anterior, é a vinculação que os alunos podem estabelecer com o ensino. Em geral, suas experiências anteriores com a escola e com a aprendizagem lhes deixaram marcas relacionadas às dificuldades reais ou imaginárias vivenciadas. Quando submetidos aos métodos tradicionais de avaliação, as dificuldades encontradas, muitas vezes representadas objetivamente na forma de notas baixas, podem se traduzir na profecia que se autorrealiza: "eles

\footnotetext{
4 Quando reconhece que a aprendizagem ocorre em diferentes tempos, por processos singulares e particulares de cada sujeito, tem ritmos próprios e lógicas diversas, em razão de experiências anteriores mediadas por necessidades múltiplas e por vivências individuais que integram e compōem o repertório a partir do qual realiza novos aprendizados, e ressignifica os antigos (Brasil, 2006, p. 54).
} 
não servem para a escola". Todavia, com a possibilidade de serem avaliados de forma processual e sem a definição de conceitos ou graus, reduzem-se bastante as possibilidades de estigmatização desses estudantes. Outros vínculos com o ensino tendem a ser estabelecidos, uma vez que a avaliação passa a se revestir de um sentido diagnóstico e dialógico, em vez de classificatório e absoluto, permitindo-lhes perceber sua utilidade no processo de aprendizagem.

Mesmo sendo uma proposta que busca reduzir as tensões, os alunos não a vivem sem resistências. $\mathrm{Na}$ dinâmica institucional, o instituído tem um peso considerável e alguns alunos não conseguem se mover nesse novo campo formado por estratégias e práticas pedagógicas cujo responsável deixa de ser única e exclusivamente o professor. As respostas que surgem estão na linha da solicitação pelo retorno do funcionamento anterior (leia-se tradicional), denotando a dificuldade de se relacionarem com a escola a partir de perspectivas diferentes daquelas nas quais a articulação entre poder e saber sustentam relações rígidas e hierarquizadas. Numa configuração instituinte, tempos e espaços de aprendizagem devem ser organizados sob novas bases, pelas quais os alunos são chamados a assumir a posição de protagonistas do processo, tanto quanto os professores.

\section{CONSIDERAÇÕES FINAIS}

A experiência relatada neste trabalho não deixa dúvidas de que os alunos também são afetados pela prática pedagógica com base em outros modelos de organização curricular. No entanto os possíveis efeitos sobre a subjetivação desses estudantes não foi objeto de análises mais detalhadas neste momento. Há muito a ser problematizado quando se percebem as transformaçōes operadas em alguns sujeitos ao longo de dois ou três semestres cursando a EJA, mas também quando se observam falas e comportamentos que denotam resistência às mudanças. No entanto, esses e outros aspectos poderão ser discutidos em outra oportunidade.

É importante destacar, todavia, que a resistência de alguns alunos à nova proposta de avaliação também produziu efeitos sobre os docentes. Diante da recusa de um grupo de estudantes em participar das atividades diversificadas (científicas, culturais e artísticas), planejadas para encerrar o semestre letivo, alguns professores se manifestaram de forma curiosa, sugerindo em tom irônico o retorno ao modelo anterior (provas, testes, etc.). No entanto, nas discussóes que foram desencadeadas a partir desse episódio, buscou-se dar visibilidade aos elementos que surgiram dessa situação, de forma a evidenciar as práticas conservadoras, os movimentos subliminares e os pensamentos inaudíveis que teimavam em se manifestar, apesar da recusa de seus agentes em admiti-los. 
Desse modo, graças à resistência dos alunos e à reação provocada nos professores, foi possível colocar em análise as dificuldades de todos: no caso dos alunos, de experimentarem o novo (aquilo que foge ao conhecido e já mapeado), mesmo que se esteja sinalizando com a redução significativa das tensões e da rigidez presentes no ensino tradicional. E, no lado dos professores, a dificuldade para lidarem com a recusa dos alunos em seguirem suas orientações. Mas não apenas isso. A rapidez com que a sugestão de retorno aos métodos tradicionais foi lembrada, ainda que em tom de brincadeira, ${ }^{5}$ pode indicar, igualmente, uma grande dificuldade dos docentes em lidarem com o desconhecido, em vivenciarem uma situação sobre a qual não têm mais o domínio que tinham antes.

Essas questôes foram analisadas, discutidas e avaliadas pelos docentes nas várias reuniōes realizadas para o planejamento e o acompanhamento pedagógico. É possível afirmar que os professores foram modificados por essa experiência. Mesmo considerando as dificuldades que alteraçôes nas práticas de trabalho instituídas costumam trazer, a motivação para enfrentá-las esteve sempre presente. $\mathrm{O}$ trabalho continuou, e a avaliação pelas fichas de acompanhamento foi mantida.

No entanto, em que pesem as possibilidades abertas no sentido de superar formas instituídas no campo da educação, há efeitos pouco explorados nesse processo. A oportunidade de construir coletivamente os projetos políticopedagógicos das instituiçôes educacionais, incluindo a redefinição dos currículos, obriga os educadores reunidos em grupos de discussão, planejamento, etc., a repensarem o seu processo de trabalho, mesmo que não seja esse o objetivo principal de propostas que defendem gestôes mais democráticas nas escolas. Como é possível observar com base na participação nos fóruns, encontros, reuniōes, etc., ou durante as discussões sobre as práticas e fazeres pedagógicos, os sujeitos acabam por empreender o que Barros (2003) chama "análise coletiva do trabalho". Segundo a autora, ao discutirem o processo de trabalho, os educadores falam dos sentimentos provocados e das vivências mobilizadas pelas circunstâncias do trabalho pedagógico, deixando à mostra a dimensão do que enfraquece e causa sofrimento, mas também permitindo a construção de novas e mais potentes análises. A autora afirma que:

Nessa direção, coloca-se a urgência de se pensar as práticas educacionais a partir da análise das questões ligadas ao trabalho real dos educadores, à história e à política, visando à potência de instituir novas normas e produzir outras formas de subjetividade, próprias do processo vital (Barros, 2003, p. 10).

Não se pode esquecer o que a psicanálise afirma em relação ao caráter revelador das motivações inconscientes relacionado aos chistes. 
Tanto o currículo integrado quanto a avaliação da aprendizagem podem ser encarados, então, como "dispositivos pedagógicos". E a presença destes nos espaços institucionais da educação permite colocar em discussão as relações e as práticas instituídas, favorecendo o surgimento de estratégias educacionais implicadas com a transformação dessas relações. Além disso, a análise de seus efeitos, funcionamento, etc., ajudam a problematizar a produção de subjetividades na sociedade atual.

Quando, então, a proposta de integração curricular é combinada com a educação de jovens e adultos, conforme se observa pelas experiências de implantação do Proeja na Rede Federal de Ensino, o seu potencial analisador sobre a Educação se amplia e seus efeitos ganham contornos mais nítidos.

A exemplo, porém, do que ocorre com a maioria das propostas que tendem a modificar os modos de funcionamento instituídos, sua efetivação não acontece sem o aparecimento de resistências. A presença dessas resistências traz, logicamente, dificuldades para a implantação de qualquer programa, política ou inovação pedagógica nos espaços educacionais, mas, por outro lado, permite observar o modo como as práticas e as relações são constituídas. Além disso, reconhecendo seus efeitos num campo mais amplo, percebe-se que evidenciam o impensado de uma instituição social como a educação, chamando a atenção para o que, até então, estava presente, porém não chegava a ser problematizado. 


\section{REFERÊNCIAS}

Adriano, I. G., Guimarães, G. \& Oliveira, F. R. Q. (2009). Relatório do I Diálogo Proeja. Rio Verde: Instituto Federal Goiano. Recuperado a partir de http://rv.ifgoiano.edu.br/periodicos/index.php/vidadeensino/article/ download/86/50

Barros, M. E. B. (2003). Por uma outra política das práticas pedagógicas. In Anais da 26 reunião anual da Anped. Poços de Caldas: Anped. Recuperado a partir de http://www.26reuniao.anped.org.br/trabalhos/06tmareb.pdf.

Brasil. Ministério da Educação. Setec. Proeja. (2006). Programa nacional de integração da educação profissional com a educação básica na modalidade de educação de jovens e adultos: texto-base. Brasília: Ministério da Educação.

Colontonio, E. M. (2010). O currículo integrado do Proeja: trabalho, cultura, ciência e tecnologia em tempos de semiformação. (Dissertação de mestrado). Universidade Federal do Paraná, Curitiba.

Larrosa, J. Tecnologias do eu e educação. (1994). In Silva, T. T. O sujeito da educação: estudos foucaultianos. (pp. 35-86). Petrópolis: Vozes.

Lopes, A. C. \& Macedo, E. (2011). Teorias de currículo. São Paulo: Cortez.

Lopes, J. (2009). Educação profissional integrada com a educação básica: o caso do currículo integrado do Proeja. (Dissertação de mestrado). Centro Federal de Educação Tecnológica, Belo Horizonte.

Machado, L. R. S. (2005, 9 de dezembro). Organização do currículo integrado: desafios à elaboração e implementação. In Anais da reunião com gestores estaduais da educação profissional e do ensino médio. Brasília: Ministério da Educação.

Menegotto, D. B., Ayub, D. M. \& Perozzo, J. P. (2009). Práxis e vozes: compartilhando as experiências nos processos de ensino e de aprendizagem no Proeja. In Zorzi, F. \& Pereira, V. A. (Orgs.). Diálogos Proeja: pluralidade, diferenças e vivências no sul do país. (pp. 64-71). Bento Gonçalves: Instituto Federal de Educação, Ciência e Tecnologia, Editora Evangraf.

Moura, B. S. P., Scopel, E. G., Zen, E. T., Silva, L. C. S., Médici, M. G. O. \& Ferreira, M. J. R. (2010). O movimento de construção dos projetos pedagógicos dos cursos do proeja no IFES. In Anais, 2 Seminário Nacional de Educação Profissional e Tecnológica, Vitória: Senept. Recuperado a partir de http://www. senept.cefetmg.br/galerias/Anais_2010/Artigos/GT7/O_MOVIMENTO_ DE_CONSTRUCAO.pdf 
Silva, V. C. N. (2010a). A implementação do Proeja na rede federal de educação profissional e tecnológica: visão dos gestores. (Dissertação de mestrado). Universidade de Brasília, Brasília. Recuperado a partir de http://repositorio. unb.br/handle/10482/8445.

Silva, V. C. N. (2010b). Da EJA ao Proeja: a transição da educação de jovens e adultos na rede federal. In Anais do 33 Encontro da Anped, Caxambu: Anped. Recuperado a partir de http://bvssite.bvseps.icict.fiocruz.br/lildbi/docsonline/ get.php?id=329

Veiga-Neto, A. (2002). Espaço e currículo. In Lopes, A. C. \& Macedo, E. (Orgs.). Disciplinas e integração curricular: história e políticas. Rio de Janeiro: DP\&A. 